\title{
Implementation Study on Applying Agile Supply Chain Paradigm in the Manufacturing of a Conventional Automobile Horn in an Indian Company
}

\author{
Ben Ruben R., Prasanth A. S., Ramesh R., and Narendran S. A. P.
}

\begin{abstract}
From the beginning of the 21th century many researchers and practitioners have been finding and implementing various concepts in organizations for facing the emerging competition. Agile Supply Chain Management (ASCM) is one of the paradigms which facilitate the organization to satisfy customer need through quick response. In this paper, we have carried out a case study in an automobile horn manufacturing company for infusing agility in the vibrosonic horn's supply chain. The current agility level has been measured and the areas of improvement have been demarcated. We have chosen two models which have been already proposed by two researches in this field for evaluating the agility level. Further we have proposed ideas for increasing current agility level
\end{abstract}

Index Terms-Agile supply chain management, agile supply chain, agility, supply chain management, case study.

\section{INTRODUCTION}

In today's business world, competitions are intensifying significantly in the volatile modern markets, where new products have been hitting the market frequently. Hence, there arises a need for any organization to look into producing several models of products to attract customers. In order to produce new products in an efficient manner, the company should understand the supply chain network of the product thoroughly. This will aid them in monitoring the flow of the product, raw materials and information flow across the supply chain. Also, for optimizing the resources and increasing the profit of the products, it is necessary to accomplish efficient Supply Chain Management (SCM). The SCM helps in increasing profit through optimization and provides expected products and services at appropriate time and appropriate place as demanded by customers [1]. Nowadays, the customers' expectations and their satisfaction levels are manifold. Thus, organizations should be able to quickly respond to the volatile market. For this, the supply chain of the company has to be more agile and flexible. There are many hidden advantages to the company if it possesses an Agile Supply Chain (ASC).

The key characteristics of the ASCs include the following features:

- Produces high product variety

Manuscript received December 25, 2012; revised February 15, 2013.

The authors are with the Department of Mechanical Engineering, PSG College of Technology Coimbatore, Tamil Nadu, INDIA (e-mail: ben.ruben21@gmail.com).
- Adapts to volatile market demand. Life cycle of the products will be probably short but the profits margin is high

- Responds easily to unpredictable changes in the market at rapid pace (reference).

- Increases the quality and reliability of the supply chain.

- Faster flow of materials, information and decisions across the organization's supply chain network.

- Manufactures the existing products at lower cost

- Manufactures new products speedily and economically.

For the past two decades researchers around the globe were carrying out researches in ASCM and reaping its benefits. Many firms implemented ASCM thus, enhancing their competitive advantage. This paper presents the implementation of ASCM in an Indian Automobile horn manufacturing company which is located in the city of Coimbatore, in the state of Tamil Nadu. This work consists of two phases. The first phase of the work is to implement agility in the supply chain of the existing horn, which is already being manufactured by the company. The second phase of the project is about testing the agility of company's supply chain by introducing a new model horn(s), which is not currently manufactured by the company .This paper reports the first phase of the work .

\section{LITERATURE SURVEY}

D. R. Towill [1] provided a time compression model for logistics information management and derived results on logistic models and complexity in supply chains. Yusuf, Y.Y et al [2] proposed a conceptual model for assessing the agile supply chain model. The author also conducted a questionnaire with 600 manufacturing companies of varied size in order to measure seven dimensions of supply chain and its impact on business performance. The results showed that the agile supply chain capabilities provide more impact on competitiveness than lean and traditional supply chains. Marcus I [3] provided a model for agile supply chain and its impact on business performances. Naylor, J.B et al [4] introduced a term Leagility, which integrates the lean and agile manufacturing paradigms in the total supply chain. Christopher, M.et al [5], proposed an integrated model for the design and complexity of agile supply chains. Christopher, $\mathrm{M}$ et al, [6] proposed ideas on creating agile supply chains in the fashion industry, which reduces the cycle time by increasing the responsiveness Van Hoek et al 
[7]identifies the drawbacks and unavailability of integrated techniques in the supply chain and developed a framework for agile supply chains. This virtual teaming concept is explained by the author by providing the example of automotive supply chain. Aurelie Charles et al [8] discusses that lead time reduction and enhancing the information flow across the supply chain will increase the agility in the supply chain. They also illustrate that the Total Cycle time reduction utilizes the synergized benefits that are available from reduction of both material and information lead time. $\mathrm{H}$. Sharifi et al [9] contributed innovative ideas on achieving agility in supply chain through simultaneous "design of" and "design for" supply chain" Manisra Baramichai., et al [10]found out that outsourcing tool has drastically enhanced the flexibility, leanness and agility of the supply chain. Rachel Mason-Jones et al,[11]framed a method for analyzing which variable enables more impact for increasing agility in supply chains. These variables were called as driver variables. Edmund Prater et al,[12] introduced Agile Supply Chain Transformation Matrix (ASCTM) tool for enhancing agility at the supplier- buyer supply chain. Here the ASCTM tool is developed by utilizing Quality Function Deployment concept. Baker, P et al [13] investigates about the designing and operation of the distribution centre that exist within the supply chain. For investigating, the author carried out case study in nine companies which were selected from manufacturing, wholesaling, retailing and direct selling. Jari Collin et al [14] discussed the Plan for supply chain agility at Nokia, Lessons from the mobile infrastructure industry, which explained the complexity of mobile industry. M.N. Faisal et al [15] projected an integrated framework model of simultaneous design of supply chain and design for supply chain in order to enhance agility at the required supply Sreenivasa C.G. et al [16] proposed 30criterias for measuring the agility level of an organization.

This paper reports about implementing agility in the supply chain of automobile horn manufacturing company No researches have been reported so far on applying Agile Supply Chain principles in automobile horn manufacturing companies.

\section{Essence of Automobile Horns}

For the past few decades, automobile companies are attaining a great improvement in production. The automobile companies are manufacturing a large number of vehicles including two wheelers, light motor vehicles and heavy motor vehicles. For every vehicle, horn is the basic device needed for safe journey. The horns help the vehicle driver to alert the people and other vehicles in the road about the coming of vehicle. The horn life will be for few years only. The increase in number of vehicles and need for new horns in the vehicles has increased the horn production dramatically in the past decades. Horns are generally divided into categories. First type is Air horn and the second type is Electric horn. They also divided into categories such as Marine horn, Truck horn, train horn, Musical horn and Motorcycle horn. All the horn manufacturing companies give different names to their horns. They also get copy rights for that horn name. The horns used in two wheelers will be small in size compared to those used in cars and heavy vehicles. All horns in Roots Industries are manufactured based on the law IS: $1884-1993$. The main factors which are taken into consideration in this law include vibration, temperature and acceleration. I S: 1884 - 1993 rules are to be adhered by all automobile horn manufacturing company.

\section{CASE Study}

The selected Automobile horn manufacturing company is the leading manufacturer of the horns in India. The company was established in 1970 at Coimbatore, the number of people working in the company is nearly 2000. It is the world's first horn manufacturing company to obtain ISO/TS 16949 certification. This company is the main supplier of horns to vehicle manufacturers like Toyota, Tata Motors, Ford, Daimler Chrysler, TVS Motor Company, Kinetic Honda, Mitsubishi Lancer, Mahindra \& Mahindra, Fiat Uno and Siena, TELCO, etc. They also export horns to 15 countries worldwide. The types of products produced by the company are: Vibrosonic, Megasonic, Vibromax, Cleartone, Vibromini, Smart tone, Wind tone-75, Wind tone-90, Spider Eco, disc brake pad, brake shoes, clutch plates, batteries for two wheelers and four wheelers. Among these types, we chose Vibrosonic horn for our project. This horn is produced in large quantity by the company. Also, this is the important horn type of the company and it is the pioneer model which helped the company leads the market. This horn type consists of more than 20 models. They differ on the basis of the battery used in the vehicle and whether low tone or high tone horn with respect to customer's demand and specifications.

\section{A. Clasification of Vibrosonic Horn}

The vibrosonic horns are classified on various aspects. It is classified as high tone and low tone depending on the sound it produces, based on the voltage of battery used in the vehicle it is classified as $6 \mathrm{~V}, 12 \mathrm{~V}$ and $24 \mathrm{~V}$. Moreover, low tone horns produce frequency in the range of $200-300 \mathrm{~Hz}$ whereas high tone horns can produce a fundamental frequency in the range of $300-400 \mathrm{~Hz}$. The sound level produced by vibrosonic horn is about 115 decibels. The horn weighs around $0.9 \mathrm{~kg}$ and it is used in cars, jeeps, vans, trucks and tractors. The customers prefer Vibrosonic horns than other type of horns because vibrosonic horn is compact in shape, produces good tone and has good life up to 3 lakhs cycles. This horn model is also available in three varieties based on the battery used in the vehicles.

\section{B. Agile Supply Chain}

The Agile Supply Chain Management project being carried out in the automobile horn company consists of two phases. In this section, the first phase of the project that is, enhancing agility in the supply chain of the horn model that is already produced by the company is presented. As the first stage of project, we selected the vibrosonic horn model for carrying out the project, because this model has a good market and produced in large number than other models. First category suppliers are procurement suppliers and the second category suppliers are outsourcing suppliers. The procurement suppliers produce components such as fasteners and other components which are standard in the market. The 
horn company procures the components from them based on their need. But, the outsourcing suppliers produce components based on the specification and needs of the horn company. The raw materials and tools required for the outsourcing suppliers were supplied by the horn manufacturing company. The supply chain network of the vibrosonic horn is shown in the Fig 2. The types of customer for the vibrosonic and all other types of horn are classified by the roots industries.

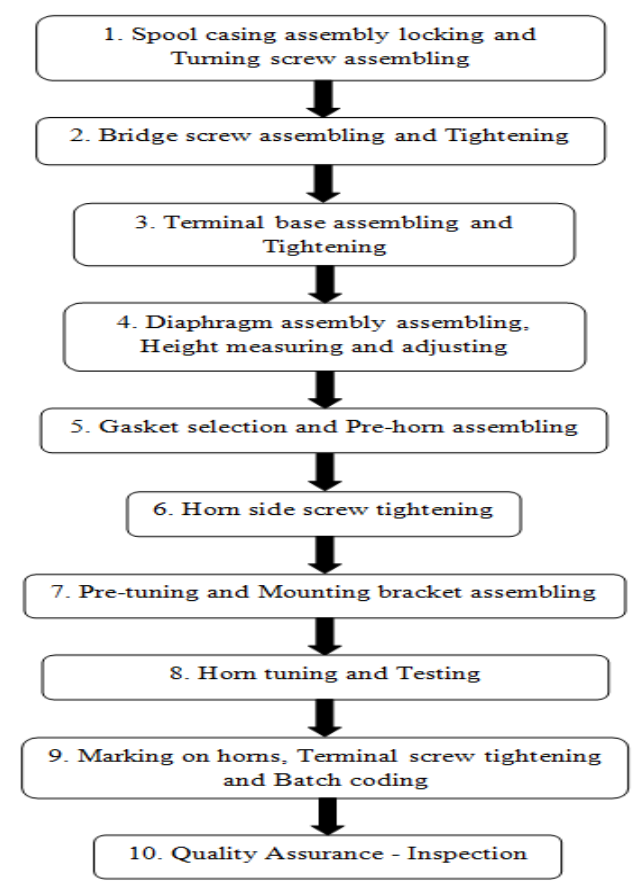

Fig. 1. Flow chart of horn assembly.

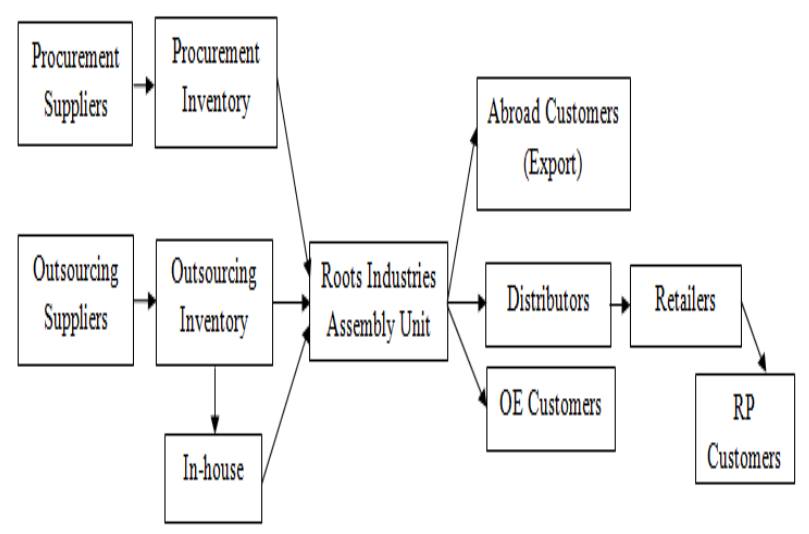

Fig. 2. Supply chain network of vibrosonic horn.

First kind of customers is named export type, these customers are in abroad and the horns are exported to them. Second kind of customers is named as OE. Companies like Toyota, Tata Motors, Ford, Daimler Chrysler, TVS Motor Company, Kinetic Honda, Mitsubishi Lancer, Mahindra \& Mahindra, Fiat Uno and Siena, TELCO were classified in this type.For the first two kinds of customers, roots manufacture horns which would be available only in the showrooms of that particular company. These horns will not be available in the retail shops. The third kind of customers is called as replacement market (RP) customers. These customers consume more than $90 \%$ of horns manufactured by the horn company. They have distributor and retailers in the supply chain network whereas the first two kinds of customers only have their company's sales and show room in the network.

The design and appearance of the horns are changed by the company in-order to attract the replacement market customers. These horns will be slightly cheaper than export and OE type horns. Also, Roots supply the horns to distributor and there will be no direct contact between the retailers or RP customers and Roots. There are totally more than 30 types of horns in vibrosonic horn model.

Customer Classification for vibrosonic horn has been discussed in the previous section. Roots industries almost meet the demands of Export and OE customers properly. But there is a lag in meeting the demands of RP customers.

We have used two criteria for measuring the agility level of the Roots company. We first chose the framework proposed by Jari Collin et al [14] . The 30 criteria for measuring agility which is proposed by[16]was chosen as second criteria in our project for measuring current agility level in Roots Industries. From the first framework by Jari Collin et al [14], we have find out the agility level tentatively would be 3 . We have found out scores for reactivity as one and score for visibility as two. However, we are yet to find the scores for velocity and after we have found out velocity score we will get the exact agility level value .For analyzing the agility contributing factors in deep we have chosen 24 criteria s from 30 criteria proposed by Sreenivasa C.G. et al [16], which is suiting for supply chain management. The chosen factors are Organization structure, Devolution of authority, Nature of management, Employees' status, Employee involvement, Team working, Manufacturing set-ups ,Product life cycle, Design improvement , Production methodology, Manufacturing planning, Automation, Information technology (IT) Integration, Customer response adoption, Change in business and technical Processes, Outsourcing, Value Chain Integration, Mass customization, Global optimization, Status of productivity, Status of quality, Time management, Flexibility, Innovation.

We have found out responses for 8 factors. The questionnaire we designed contained some sets of questions for each factor. We requested various authorities from Roots Industries to fill it. And based upon the each response the score varies. For example, in case of design improvement we totally had 7 questions and the total score for this factor is 15 . From the responses we found out the Roots Company got 14 out of 15 and the percentage is 93.3333.Likewise the percentage for 8 factors has been calculated. We found out the percentage for each factor. They are listed in the Fig. 3.

\begin{tabular}{|c|c|c|}
\hline S .No & Criteria & Percentage \\
\hline 1 & Product life cycle & 100 \\
\hline 2 & Design Improvement & 93.3333 \\
\hline 3 & Information technology (IT) Integration & 80 \\
\hline 4 & Customer Response adoption & 90 \\
\hline 5 & $\begin{array}{c}\text { Change in Business \& Technical } \\
\text { Processes }\end{array}$ & 100 \\
\hline 6 & Outsourcing & 73.33333 \\
\hline 7 & Value Chain Integration & 90 \\
\hline 8 & Innovation score & 73.3333 \\
\hline
\end{tabular}

Fig. 3. Percentage level for the selected factors. 
The resulting is the percentage gap for corresponding factors. We are suggesting improvement ideas to the company based upon their response to all the 24 criteria for measuring agility.

The percentage gaps for the selected factors are shown in the Fig 4. Also, we are finding the values for different metrics of Supply chain. First is the inventory turn of the vibrosonic model has been estimated. It is obtained as 7 turns.

Inventory turns $=$ Annual sales/Total investment in inventory

$$
\begin{aligned}
& =1,21,67,43,248 / 18,39,76,258 \\
& =6.613588412
\end{aligned}
$$

Generally for high agility in supply chains Information Flow and Materials flow should flow without any hurdles and delay. In Roots, SAP has been used to control material flow and Lotus notes for Information flow. Additionally, SMS portal system has been used for alerting the suppliers about the orders. All the customers in the customer end do not have a proper portal system for updating the stocks. So, we have suggested the company to implement the portal system at the customer end which will enhance the agility and create a transparent nature about the customers and give proper picture about the customer demands and needed horn quantity.

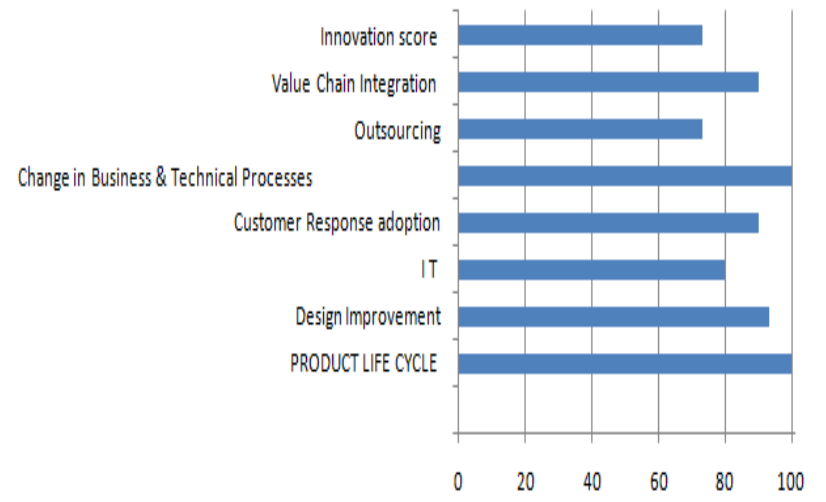

Fig. 4. Percentage gaps for the selected factors.

Roots are currently not following On-line selling method because they have some problems in maintaining the cash flow and getting the sales money.

\section{RESUlTS AND DisCUSSION}

We are suggesting some ideas for enhancing the speed of materials and information flow in the Roots Industries. We have analyzed the agility percentage gap for 24 criteria and pictured which factor affects the agility level. This helps the company to concentrate on the required area for enhancing the agility. There were some difficulties encountered on achieving the results. Roots are the world's first horn manufacturing company to get ISO/TS 16949 certification. They are following a structured system for their manufacturing horn. They also have no big competitors in India, so they do not worry about introducing new models frequently. They are producing new horn models only when the OE customers demand for it. So, the company is concentrating on improving the agility of their existing supply chain and hence we found little difficulties in explaining about the need and importance of infusing agility in the supply chain of vibrosonic horn.

\section{CONCLUSION}

In the past decades, the automobile companies have achieved a great development. Since horn is the basic device needed for every vehicle, increasing demand in automobile market has automatically triggered a growing market for automobile horns. The individuals who drive the vehicle like different tones, aesthetic appearances, models and size of horns. Thus, a demand for many models of automobile horn has been developed drastically. In order to cope up with the demands and achieve huge profit the horn manufacturing organizations should be agile. To regulate the numerous numbers of horn models and their production the supply chains with agile characteristics are to be employed in the organizations. In this project, efforts were made to infuse the agility in the supply chain of the automobile horn manufacturing company. First, the current status of the supply chain has been studied and then the improvements for agility are suggested. The first phase of the project has been reported in this paper and it deals about infusing the agility in the supply chain of the product being currently manufactured. And, in the second phase the agility of supply chains when new products are to be produced is to be examined.

\section{ACKNOWLEDGMENT}

The first four authors of this paper are thankful to the Roots Company for providing permission and co-operation for conducting case study reported in this paper.

\section{REFERENCES}

[1] D. R. Towill, "Time compression and supply chain management- a SCM guided tour," Logistics Information Management, vol. 9, no. 6, pp. 41-53,1996.

[2] Y. Y. Yusuf, A. Gunasekaran, E. O. Adeleye, and K. Sivayoganathan, "Agile supply chain capabilities: Determinants of competitive objectives," European Journal of Operational Research, vol. 159, pp. 379-392, 2004.

[3] I. Marcus, "Agile supply chain: Strategy for competitive advantage," Journal of Global Strategic Management, June 07, 2010.

[4] J. B. Naylor, M. M. Naim, and D. Berry, "Leagility: Integrating the lean and agile manufacturing paradigms in the total supply chain," International Journal of Production Economics, vol. 62, no. 1-2, pp. 107-18, 1999.

[5] M. Christopher, D. R. Towill, "An integrated model for the design of agile supply chains," International Journal of Physical Distribution and Logistics Management, vol. 31, no. 4, pp. 235-246, 2001.

[6] M. Christopher, R. Lowson, and H. Peck, "Creating agile supply chains in the fashion industry," International Journal of Retail and Distribution Management, vol. 32, no. 8, pp. 367-76, 2004.

[7] R. I. V. Hoek, A. Harrison, and M. Christopher, "Measuring agile capabilities in the supply chain," International Journal of Operations and Production Management, vol. 21, no. 1-2, pp. 126-47, 2001.

[8] A. Charles, M. Lauras., L. V. Wassenhove, "A model to define and assess the agility of supply chains: Building on humanitarian experience," International Journal of Physical Distribution and Logistics Management, vol. 40, no. 8-9, pp. 722-741, 2010.

[9] H. Sharifi, H. S. Ismail, and I. Reid, "Achieving agility in supply chain through simultaneous "design of" and "design for" supply chain," Journal of Manufacturing Technology Management, vol. 17 no. 8, pp. 1078-1098, 2006. 
[10] M. Baramichai, E. W. Zimmers Jr., and C. A. Marangos, “Agile supply chain transformation matrix: An integrated tool for creating an agile enterprise," Supply Chain Management, vol. 12, no. 5, pp. 334-348, 2007.

[11] R. M. Jones, B. Naylor, and D. R. Towill, "Engineering the leagile supply chain," International Journal of Agile Management Systems, vol. 2, no. 1, pp. 54-61, 2000.

[12] E. Prater, M. Biehl, and M. A. Smith, "International supply chain agility," International Journal of Operations \& Production Management, vol. 21, pp. 823-839, 2001.

[13] P. Baker, "The design and operation of distribution centres within agile supply chains," International Journal of Production Economics, vol. 111 , pp. 27-41, 2008.

[14] J. Collin and D. Lorenzin, "Plan for supply chain agility at Nokia, Lessons from the mobile infrastructure industry," International Journal of Physical Distribution and Logistics Management, vol. 36, no. 6, pp. 418-430, 2006.

[15] M. N. Faisal, D. K. Banwet, and R. Shankar, "Supply chain agility: Analysing the enablers," Agile Systems and Management, vol. 2, no. 1, pp. 76-91, 2007.

[16] C. G. Sreenivasa, S. R. Devadasan, and R. Murugesh, "Thirty criteria-based assessment of agility in a pneumatic enabling products manufacturing company," International Journal of Services and Operations Management, vol. 11, no. 2, 2012.

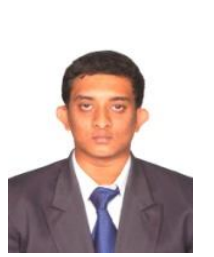

R. Ben Ruben was born at Coimbatore, Tamil Nadu, India on 17 October 1989. He did his bachelor of engineering in the field of production engineering sandwich stream (a five year integrated course with industrial training) at PSG College of Technology Coimbatore, Tamilnadu India in the year 2012.Later he joined his master of engineering program in the field of Lean Manufacturing at PSG College of Technology Coimbatore ,Tamil Nadu India. Currently he is studying his first year of his master program. His area of interest includes lean manufacturing, agile manufacturing, supply chain management and lean six sigma. The author has done projects in the area of agile supply chain management, value stream mapping, and six sigma. The author also published a paper on agile project management in the international conference of operations and management (IEOM 2012) held at Istanbul, Turkey in the year 2012.

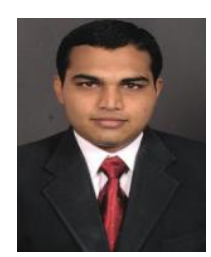

Prasanth A. S. is from Coimbatore, Tamil Nadu, India. He did his undergraduate programme in the field of mechanical engineering at PSG College of Technology Coimbatore Tamilnadu India. He did his post graduate programme in industrial engineering at Wayne State University Detroit, USA .Currently the author works as an assistant professor at PSG College of Technology Coimbatore India. His areas of interests includes lean operations, simulation and modelling, lean six sigma and supply chain management

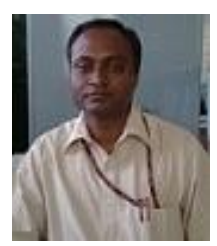

Ramesh R. is from Coimbatore, Tamil Nadu, India. He did his undergraduate programme in the field of mechanical engineering MepcoSchlenk Engineering College, Sivakasi Tamil Nadu India. He did his post graduate programm in the field of design engineering at Kongu Engineering College, Erode, Tamil Nadu India. $\mathrm{He}$ did his doctorate programme in the field of dimensional modelling and analysis at National Institute of Technology, Trichy Tamil Nadu India. Currently the author works as an assistant professor at PSG College of Technology Coimbatore India.

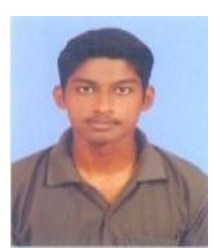

Narendran S. A. P. was born at erode, Tamil Nadu, India on 6 June 1990.He did his bachelor of engineering in the field of industrial engineering at College of Engineering (Anna University) Chennai Tamil Nadu India in the field of lean manufacturing at PSG college of Technology Coimbatore, Tamil Nadu India. Currently he is studying his first year of his master program. 